\title{
O RECONHECIMENTO DA CIDADANIA ITALIANA COMO FATO, VALOR E PROCESSO: O PASSAPORTE COMO SÍMBOLO DE ITALIANIDADE
}

\author{
The recognition of Italian citizenship as fact, value and process: \\ the passport as a symbol of italianity
}

\author{
Jamile Dos Santos Pereira Costa* \\ Maria Catarina Chitolina Zanini**
}

\begin{abstract}
Resumo. Este artigo é resultado de pesquisa etnográfica que temos desenvolvido entre/com ítalo-brasileiros em Santa Maria e cidades da Quarta Colônia de Imigração Italiana/RS, Brasil. Nosso objetivo é analisar as dinâmicas envolvidas no processo de reconhecimento legal da cidadania italiana, bem como o valor atribuído ao passaporte italiano. Observamos que o passaporte, para além de um documento (objeto), cristaliza valores afetivos e simbólicos que o tornam mais relevante que o tempo de espera pela cidadania e o custo econômico que esse processo demanda.
\end{abstract}

Palavras-Chave: dupla cidadania; ítalo-brasileiros; passaporte.

\begin{abstract}
This paper is the result of an ethnographic research that has been developed between/with Italian Brazilian in Santa Maria and in the towns of the Fourth Colony of Italian immigration (RS - Brazil). Our objective is to analyze the dynamics involved in the process of recognition of Italian citizenship, as well as the value attributed to the Italian passport. We observed that the passport, besides a document (object), crystallizes affective and symbolic values that make it more relevant than the waiting time for the citizenship and the economic cost that this process demands.
\end{abstract}

Keywords: dual citizenship; Italian Brazilians; passport.

Mestra em Ciências Sociais pelo Programa de Pós-Graduação em Ciências Sociais da Universidade Federal de Santa Maria (PPGCS/UFSM). E-mail: mile_rec@hotmail.com. Orcid: 0000-0002-9042-715X.

** Professora associada da Universidade Federal de Santa Maria, vinculada aos programas de PósGraduação em Ciências Sociais (PPGCS) e História (PPGH) da UFSM. E-mail: zanini.ufsm@ gmail.com. Orcid: 0000-0003-4523-9915. 


\section{Introdução}

O presente artigo é fruto de pesquisa ${ }^{1}$ que buscou observar as narrativas e percepções de descendentes de imigrantes italianos sobre o processo de reconhecimento legal de "ser ítalo-brasileiro" na região central do Rio Grande do Sul (RS). A pesquisa partiu de um estudo etnográfico entre/com descendentes de italianos na cidade de Santa Maria e também em localidades da Quarta Colônia de Imigração Italiana ${ }^{2}$, uma vez que muitos de nossos interlocutores são naturais dessas cidades ou descendem de imigrantes que lá residiram. Há toda uma produção memorialista local acerca do pertencimento ao mundo italiano de origem de seus antepassados e uma "italianidade" constantemente atualizada e reafirmada (Zanini, 2007). Para Zanini (2006), por italianidade, entendem-se os vínculos de pertencimento dos descendentes de imigrantes italianos locais com a "origem italiana" de seus antepassados. Trata-se de uma construção valorativa que se atualiza e refaz, mas que faz muito sentido para os descendentes que pesquisamos. Nosso interesse em desenvolver este estudo parte do entendimento de que o processo de reconhecimento da dupla cidadania e seus desdobramentos (como a obtenção do passaporte, por exemplo) são objetos de pesquisa importantes, pois representam mais que um direito político que esses cidadãos de fato possuem, uma vez que carregam valores simbólicos e afetivos que passam pelas histórias familiares dessas pessoas. Além disso, são questionamentos que vêm sendo analisados

1 Foram dois projetos de pesquisa que orientaram a busca por respostas quanto aos processos de dupla cidadania. Um deles, denominado Dupla Cidadania: duplos pertencimentos? Um estudo sobre os ítalo-brasileiros no Rio Grande do Sul, foi coordenado por Maria Catarina Chitolina Zanini e financiado pelo CNPq, a quem agradecemos. Outro projeto foi derivado do primeiro e possibilitou a dissertação de mestrado de Jamile Dos Santos Pereira Costa, intitulada Dupla cidadania: ítalo-brasilianidade como valorização e afirmação étnica no sul do Brasil. 2017. Dissertação (Mestrado em Ciências Sociais) - Universidade Federal de Santa Maria. Santa Maria, RS, 2017. A pesquisa teve caráter etnográfico e foi desenvolvida entre os anos de 2013 a 2017. Utilizamos como técnicas a observação participante junto aos descendentes com reconhecimento legal da cidadania italiana, em eventos como, as "Festas de Família" que celebram a cultura italiana na região de Santa Maria e da Quarta Colônia de imigração italiana no Rio Grande do Sul. Também fizemos uso da observação não participante junto à Associação Italiana de Santa Maria (AISM) e na Agencia Consular da Itália em Santa Maria. Fez-se uso também de entrevistas semi-estruturadas. Foram entrevistadas 15 pessoas, sendo 8 jovens na faixa etária entre 18 a 30 anos e 7 entrevistas com descendentes entre 35 a 70 anos, todos com processo legal de reconhecimento da cidadania italiana finalizado. Destacamos também, que a escolha dos entrevistados e as respectivas faixas etárias se deu por entendermos que as motivações para a busca do reconhecimento da cidadania mudam de acordo com as gerações e isso precisava ser considerado.

2 Representa o quarto núcleo de colonização italiana no Rio Grande do Sul. Foi o primeiro núcleo constituído fora da Serra Gaúcha. A Quarta Colônia agrega, atualmente, os municípios de Nova Palma, Faxinal do Soturno, Silveira Martins, Ivorá, Pinhal Grande, São João do Polêsine, Dona Francisca, Agudo e Restinga Seca, sendo de colonização mista (italianos, alemães e portugueses) esses últimos três municípios aqui destacados (Manfio, Benaduce, 2010, p. 1; Santos, Zanini, 2009, p. 22). 
em outros contextos de imigração ${ }^{3}$ italiana no Brasil, mas que ainda eram pouco observados na região central do Rio Grande do Sul, na qual muitos descendentes de imigrantes italianos residem até hoje.

Segundo dados informais coletados junto à Agência Consular da Itália em Santa Maria, só na região central do Estado haveria em torno de 4.000 cidadanias italianas reconhecidas (Costa, 2017, p. 13). Esses duplos cidadãos possuem uma série de direitos garantidos na Itália e passam a fazer parte da AIRE (L'Anagrafe italiani residenti all'estero - Anagrafe para os italianos residentes no exterior). A anagrafe foi instituída em 27 de outubro de 1988, pela Lei no 470, para acompanhar aqueles cidadãos italianos que se encontram há mais de 12 meses fora da Itália ${ }^{4}$. Trata-se de um censo, no qual os descendentes que possuem dupla cidadania, mas residem no exterior são classificados como "italianos residentes no exterior" (IRE - Italiani residenti all'estero). Esses duplos cidadãos devem manter seu cadastro sempre atualizado junto ao órgão italiano, com dados tais como endereço, estado civil, formação familiar e outros. Do ponto de vista jurídico são considerados cidadãos italianos com plenos direitos, podendo votar e opinar em situações relativas à Itália. Estando lá, têm direito aos serviços de saúde, educação, previdência e outros, desde que sigam as instruções normativas solicitadas. São também denominados oriundi, e alguns utilizam a designação "ítalo-brasileiros".

Esses ítalo-brasileiros são descendentes dos imigrantes italianos que chegaram ao Brasil entre os séculos XIX e XX e que, hoje, buscam o reconhecimento formal da sua cidadania, direito esse que é garantido pelo Estado italiano. A migração de italianos para a região central do Rio Grande do Sul começou em 1877. Tratava-se de uma migração familiar, de camponeses pobres e católicos do norte da Itália em sua maior parte. Vieram por meio de acordos entre o governo brasileiro imperial e a Itália. Aquela emigração italiana em massa deve ser compreendida como algo intrinsecamente vinculado ao desenvolvimento do capitalismo na Itália, no sentido econômico, social, político e cultural. Muitas das famílias que hoje solicitam o reconhecimento da dupla cidadania são descendentes das primeiras famílias que para cá vieram em finais do século XIX e início do XX.

A nacionalidade italiana (Piccoli, 2013) é regulamentada pela Lei no 91, de 5 de fevereiro de $1992^{5}$. Até 1912, com a Lei no 555, de 13 de junho de

\footnotetext{
3 Estudos sobre dupla cidadania italiana foram desenvolvidos em Santa Catarina, por Adiles Savoldi (O caminho inverso: a trajetória de descendentes de imigrantes italianos em busca da dupla cidadania. 1998) e por Mariângela Porto Braga (Descendentes de imigrantes italianos em Belo Horizonte e o impacto da dupla cidadania na construção da identidade ítalo-brasileira, 1990 a 2008. 2009), em Belo Horizonte. Esses estudos serviram de base para compreendermos o processo e suas dinâmicas no cenário de nossa pesquisa.

4 Informações: <http://www.esteri.it/mae/it/italiani_nel_mondo/serviziconsolari/cittadinanza.html>.

5 Informações: <http://www.esteri.it/mae/it/servizi/stranieri/cittadinanza_0.html>.
} 
1912, a cidadania era transmitida aos filhos apenas por linha paterna, como constata Stolf (2012, p. 56), independentemente do local de nascimento. Essa medida fazia parte da nova política italiana que pregava uma única identidade nacional, independente do território, limitando ao máximo as nacionalidades múltiplas. Não há um limite geracional para a solicitação do reconhecimento da cidadania por descendentes de italianos em linha reta paterna. $\mathrm{Na}$ linha genealógica, quando houver mulher, a cidadania só é concedida ao descendente se tiver nascido após 1ํ de janeiro de 1948. É importante destacar que os direitos de transmissão via materna só foram possíveis a partir de 1948, quando a Itália passou a ser uma república e repensou e reconheceu a igualdade entre homens e mulheres juridicamente. Antes da data de $1 \underline{0}$ de janeiro de 1948, a Itália era um reino. Segundo as leis, o princípio de igualdade não pode retroagir, de modo que a transmissão via materna só pode ser reconhecida aos nascidos após a Constituição da República Italiana, deixando, assim, muitos descendentes sem a possibilidade de abrir processos de reconhecimento ${ }^{6}$.

Outra questão que preocupa e causa desânimo aos descendentes que buscam por esse reconhecimento é o sistema de atendimento junto aos consulados, que é considerado muito demorado e burocratizado. Há, segundo os descendentes, "filas intermináveis" de espera pelo reconhecimento da cidadania. Especialmente nos consulados de São Paulo, Curitiba e Porto Alegre (que é onde são encaminhados os processos de reconhecimento provenientes do Rio Grande do Sul), a fila de espera pelo reconhecimento tem chegado a até 15 anos.

Essa demora acontece principalmente pela falta de funcionários para suprir uma demanda tão grande de processos, além da crise financeira das instituições que acaba impedindo a contratação de novos digitadores, como constatou o cônsul-geral da Itália em Porto Alegre, Nicola Occhipinti, em entrevista ao jornal Zero Hora, em 19 de outubro de 2016, reeditada pela revista Insieme - A revista italiana daqui, em 21 de outubro de 2016 (Peron, 2016). Desse modo, ter toda a documentação em mãos antes de entrar com o processo é fundamental, e é nesse momento que a reconstrução das sagas familiares começa a se desenvolver (Costa, 2017, p. 55). Há uma série de documentos que necessitam ser comprovados ${ }^{7}$, tais como certidões de nascimento, casamento e óbito de toda a linhagem, desde o emigrado até o descendente atual. Muitas famílias não sabem de qual localidade italiana partiram seus antepassados. Na região central do estado, há vários locais em que se pode obter ajuda no sentido de "desvendar" algumas informações,

\footnotetext{
6 Ibidem.

A lista dos documentos necessários e de como encaminhar o processo de reconhecimento pode ser consultada no site: <http://www.consportoalegre.esteri.it/consolato_portoalegre/it/>.
} 
como a Agência Consular Italiana, a AISM (Associação Italiana de Santa Maria) e o Arquivo Histórico de Nova Palma, em seu acervo de genealogia. As igrejas e cartórios também têm sido locais de pesquisa genealógica importante, pois permitem estabelecer a ordem cronológica e os ciclos de vida dos antepassados.

Com um decreto da Presidência da República de 29 de janeiro de 2016, foi homologada a "Convenção de Haia", na qual o Brasil firmou compromisso em eliminar exigências sobre a legalização de documentos públicos estrangeiros. Tal convenção consiste em reunir em uma única apostila todas as informações que forem necessárias para que um documento em outra nação seja validado. Essa medida foi bem recebida pela comunidade italiana no Brasil, pois se entende que isso torna o processo de reconhecimento da dupla cidadania menos oneroso e burocrático (Costa, 2017, p. 58).

O fenômeno da dupla cidadania tem ganhado força nas últimas décadas devido a sua importância dentro de contextos transnacionais, uma vez que traz muitas vantagens aos que a conquistam. Traz, também, melhor mobilidade entre os países da União Europeia, por meio do Acordo Schengen de livre circulação aos cidadãos dos países membros, do qual a Itália faz parte. Há, igualmente, uma série de acordos entre Brasil e Itália, que possibilitam a esses descendentes estudar, trabalhar e fazer intercâmbios, sem maiores dificuldades nas fronteiras.

Esses são alguns fatores que impulsionam a busca pelo reconhecimento da cidadania italiana, mas existem motivações diversas e que variam com o tempo e o espaço. O passaporte é denominado carinhosamente pelos descendentes de italianos como "o vermelhinho" e sua posse é um atributo muito importante, como nossas pesquisas têm apontado. Esse documento cristaliza o processo, tornando-se um símbolo visível do percurso migratório de seus antepassados também. Ele, igualmente, materializa a história familiar e, em algumas situações de montagem de processos de reconhecimento de cidadania, faz com que a família extensa, descendente do mesmo emigrado, possa, de fato, conhecer e se reconhecer enquanto família consanguínea e reviver a família como um valor muito caro aos italianos e seus descendentes.

\section{Dupla cidadania, duplos pertencimentos? Quais e como?}

É importante fazermos alguns apontamentos quanto ao processo de reconhecimento da cidadania italiana para compreendermos a importância do passaporte para aqueles que o requerem. A cidadania nacional se apresenta de duas (Braga, 2009) formas quanto à questão de pertencimento: uma vinculada às ordens sociais e jurídicas atribuídas a um indivíduo de acordo com o seu pertencimento de solo, jus soli, e outra relacionada a um pertencimento afetivo (ou não) a outra nacionalidade, em razão das relações de sangue, jus sanguinis. Cidadania, nesse sentido, como vínculo jurídico-político de um 
indivíduo com um Estado. Havendo mais de um pertencimento, haverá mais de uma cidadania e mais de um passaporte. Isso possibilita o que Anderson (2005) denomina de "nacionalismo portátil", em que os indivíduos podem optar, quando for possível, fazer uso da cidadania que, naquele momento, mais Ihe favorecer. É o caso do uso do passaporte italiano pelos ítalo-brasileiros. Estes ressaltam que, com o "vermelhinho", são muito melhor tratados em aeroportos e serviços em geral.

Diante dessa compreensão, entendemos a dupla cidadania ítalo-brasileira como um direito atribuído a alguns indivíduos de possuírem sua nacionalidade de solo, ligada ao lugar onde nasceram e, também, sua cidadania de sangue, vinculada a sua ascendência, mantendo vínculos simultâneos com dois Estados nacionais distintos ${ }^{8}$. Os descendentes que passaram pelo processo de reconhecimento de sua origem italiana por meio de comprovação documental são classificados pelo Estado italiano como cidadãos italianos residentes no exterior (all'estero) (Costa, 2017, p. 49). Na Itália, possuem registros e são, do ponto de vista jurídico, considerados cidadãos plenos. Para Zincone (2006), a busca pela cidadania via ascendência geraria um "familismo legal", que não acompanha a sociedade civil e suas regras, uma vez que muitos desses descendentes nem falam a língua italiana e pouco ou nada conhecem da cultura do país do qual solicitaram a cidadania. A Itália que muitos dos ítalobrasileiros imaginam é a Itália dos antepassados, que já não existe mais.

Alguns autores (Reis, 2004, p. 154) observam a nacionalidade como uma condição atribuída ao indivíduo independentemente de sua vontade e, dentro dessas condições, os fluxos migratórios acabam alterando as dinâmicas entre territórios, Estados e povos. Isso condiciona os países a adotarem novas políticas sobre imigração e cidadania, para que os direitos à nacionalidade e território sejam garantidos (Costa, 2017, p. 49).

O passaporte italiano acaba servindo como uma porta para novas oportunidades em terras estrangeiras. São nessas experiências no exterior que algumas situações não agradáveis acabam acontecendo, como se observa em muitos relatos de ítalo-brasileiros na Itália. Muitos partem com sonhos e expectativas que acabam não sendo correspondidas, ao se depararem com uma Itália muito diferente daquela que Ihes foi apresentada nos relatos de seus antepassados. O mundo italiano do qual supunham fazer parte fazia sentido no Brasil, mas não na Itália, onde os ítalo-brasileiros enfrentam problemas cotidianos como o domínio da língua, o acesso aos serviços públicos e ao

\footnotetext{
8 "Em consequência da Emenda Constitucional de revisão no3, de 09/06/94, não são mais passíveis de perder a nacionalidade brasileira aqueles cidadãos que adquirirem outra nacionalidade em consequência de imposição de naturalização pela norma estrangeira ao brasileiro residente em Estado estrangeiro, como condição para permanência em seu território ou para o exercício de direitos civis". Fonte: <http://cgroma.itamaraty.gov.br/pt-br/nacionalidade.xml>.
} 
emprego. E, ali, nessas situações, são classificados como "brasileiros". Nesse trânsito de lugares, sentem-se transnacionais, pertencentes a dois mundos, o brasileiro e o italiano (real e imaginado).

A transnacionalidade (Ong, 1999) é uma categoria de grande importância no cenário das migrações por criar uma nova ideia de pertencimento entre aqueles que se encontram na vida cotidiana dos processos migratórios (Costa, Zanini, 2016, p. 1085-1086). As relações desencadeadas pelo transnacionalismo promovem uma teia de relações que aproxima o país de origem desse migrante ao país em que está residindo, mantendo-se uma ligação com ambos os pertencimentos por meio de uma organização social e/ou econômica (Schiller, Basch, Blanc, 1995). Isso possibilita que algumas relações se intensifiquem nesse contexto transnacional (Vertovec, 2009). Há, ainda, com o uso das novas tecnologias de comunicação, todo um universo de pertencimentos que se cruza no tempo e no espaço dos processos migratórios (Zanini, 2012).

Apesar das facilidades que a dupla cidadania possibilita a esses descendentes, ela não representa um nível de igualdade entre ítalo-brasileiros e italianos de solo. Os ítalo-brasileiros, por meio dos relatos que obtivemos, são tratados como "extracomunitários" e migrantes comuns, como estrangeiros de fato. Esses choques se tornam ainda mais expressivos quando se trata de mulheres ítalo-brasileiras, levando em consideração a imagem pejorativa que a mulher brasileira carrega no exterior (Costa, 2017, p. 60). Em nossa pesquisa, encontramos muitos depoimentos neste sentido:

A primeira vez que eu fui pra Itália, 1994, éramos um grupo que íamos fazer um curso de italiano na Universidade de Perugia. Eu fui antes e fiquei três dias em Roma. No horário combinado, estava no aeroporto esperando o pessoal. Da frente do aeroporto partiria o ônibus que nos levaria a Perugia. Mas, na hora marcada, não chegou ninguém. Perguntei em todos os lugares possíveis e a resposta era que o tal voo havia chegado, mas não me davam informação sobre as pessoas. Cansei de perguntar e me acomodei para fazer a única coisa possível: esperar. Não conseguia entender a situação. Horas depois, vi as colegas e nos encontramos: tinham sido detidas numa sala por suspeitarem que, sendo brasileiras, entrariam na Itália para serem "bailarinas". O problema só foi resolvido depois de muitos telefonemas. De nada adiantou dizerem e provarem que estavam chegando para estudar italiano para depois ensiná-lo aqui no Brasil. Esse é o caso mais grave de preconceito de que me lembro. (llda, 69 anos) $)^{9}$

\footnotetext{
9 Por questões éticas, todos os nomes de interlocutores da pesquisa são fictícios. Para manter a integridade e originalidade do que foi proferido pelos entrevistados, a revisão textual foi direcionada apenas para questões ortográficas e de pontuação. Desse modo, questões de sintaxe e concordância não foram alteradas. Consideramos que respeitar o ponto de vista e a privacidade dos interlocutores é primordial para uma relação de parceria e troca na pesquisa de campo.
} 
Mesmo não tendo acontecido diretamente com todos os nossos interlocutores, muitos tinham algum relato para contar sobre ítalo-brasileiros que sofreram preconceito ou passaram por algum constrangimento na Itália.

A primeira vez que eu fui pra Itália, como eu era solteira e sou ainda, o que mais me diziam era que eu tinha que ter cuidado, porque mulher brasileira não era bem vista na Itália, porque eles tinham a imagem do Brasil carnaval futebol, e isso falaram muito lá, no... O vice-cônsul aqui de Porto Alegre disse que lá ele falou, até interessante essa pesquisa que ele falou, que fizeram uma pesquisa na Itália com relação, assim, como italiano via o Brasil? E com pessoas de nível de escolaridade bom, né!? E, pra eles, Brasil, assim, é carnaval, futebol, prostituição. (Norma, 59 anos)

Alguns autores já argumentavam sobre a imagem criada da dupla cidadania como um amparo (Tedesco, 2014, p. 118-119), que, na prática, não ocorre. As noções de pertencimento a uma nação enquanto "comunidades imaginadas" (Anderson, 2008, p. 30) vão além das questões de natureza jurídico-política, elas estão em grande parte associadas a processos simbólicos e culturais mais amplos e complexos. Observamos que os descendentes de imigrantes italianos são entendidos enquanto grupo étnico, como categoria de atribuição e identificação, sustentada pelos próprios membros do grupo, que se organizam, mantêm valores e costumes, a fim de identificarem-se entre si e para os outros (Barth, 2000). Na Itália, são classificados como "brasileiros" e nas relações interativas é deles esperado que se comportem de acordo com os estereótipos que os italianos possuem dos brasileiros. Quando não há essa correspondência, costuma haver surpresas nas interações.

Ouvimos muitos relatos de ítalo-brasileiras que foram estudar ou trabalhar na Itália contando que os italianos se surpreendiam com a constatação de que elas, de fato, estudavam e trabalhavam, de que não haviam ido para a Itália "arranjar marido" ou se divertir e de que não estavam disponíveis para relações afetivas e sexuais como o estereótipo apresenta as mulheres brasileiras. Nesse sentido, os sinais adscritivos elaborados nos processos de contato étnico são sempre uma negociação que se refaz continuadamente em jogos interativos e políticos, por vezes, mais amplos. Conhecer e se reconhecer nesses jogos interativos foi um processo muito rico para alguns ítalo-brasileiros:

De um modo geral, eu percebo que a maioria do pessoal se frustra quando volta, porque eles acham que as pessoas têm obrigação de compreender o português lá, e não é assim, né!? Lá, eles são mais ou menos, não posso dizer assim como os franceses assim com a língua, mas, de uma certa forma, eles valorizam muito, assim, quando a pessoa chega falando o idioma e, mais ainda, quando chega falando o dialeto, assim. Então, eles me tratavam como se eu fosse alguém da casa deles. Assim, eu fui lá arrumar um lugar pra dormir, por exemplo, e um lenhador lá da montanha me hospedou por dois meses de graça, fiquei ajudando 
ele a trabalhar lá porque eu quis. O cara foi 100\% meu pai, assim, e muito respeito por mim, assim como eu tenho por eles, até por estar ainda muito ligado ao estilo, assim, que eles tinham de pensamento na época, pelo menos uma parte nossa aqui dos imigrantes. (Gabriel, 27 anos) (Costa, 2017, p. 61-62)

Observamos que, mesmo que os laços com a Itália dos ancestrais se faça presente por meio dos sobrenomes e de seus traços mais particulares, esses ítalo-brasileiros quando chegam à Itália e percebem que não são reconhecidos pelos italianos de solo como "um dos seus" (Zanini, Assis, Beneduzi, 2015) notam surgir sua "brasilidade" (Savoldi, 1998, p. 121). Na pesquisa, identificamos, também, que a percepção sobre ser um cidadão "italiano" muda conforme as configurações do tempo e do espaço. Traçando um recorte geracional, no qual entrevistamos descendentes jovens (entre 18 e 30 anos) e adultos-idosos (entre 35 e 70 anos), foi possível constatar que a cidadania italiana carrega outros valores e sentimentos de acordo com cada faixa etária. Os descendentes mais idosos, por exemplo, possuem maior apego às origens e uma idealização sobre a Itália de seus ancestrais, com um melhor conhecimento da história, dos costumes, das tradições familiares que vieram com os primeiros imigrantes.

Eu digo que eu sou uma pessoa que eu convivi muito com os meus avós, e eu digo, hoje, pras outras gerações da minha família, que quem puder aproveite seus avós, porque é uma coisa assim que a gente jamais esquece. E eu ia muito nas férias na casa dos meus avós, tanto por parte de pai como de mãe. E com meu avô paterno eu conversava muito, e eu me lembro que eu estava no ginásio em São João do Polêsine, e nós tínhamos uma disciplina que se chamava Relações Humanas, e o professor mandou fazer uma pesquisa nesse trabalho da árvore genealógica, e eu me lembro que aquele dia eu voltei do colégio e, em vez de ir pra casa, eu fui pra casa do meu avô paterno e, com ele, de noite, eu escrevi a árvore genealógica e, por isso, que eu sei alguma coisa daquela época que eu estava no ginásio, não tinha nem pretensão, assim... Então, eu acho, assim, até as raízes aí tu começa a ouvir a história da imigração e pensando assim: o que que levou esse meu bisavô, com 40 anos, a mulher sair de lá com 39, pra um país que eles não conheciam nada, não sabiam o que esperavam, que não era bem o que eles esperavam, era uma situação talvez muito caótica pra eles lá pra tomarem essa decisão com a vontade de ter... Então, assim, pra mim, isso tinha um valor tão importante dessa vontade de mudar, de ir em busca de uma coisa que eles nem conheciam, que eu me interessei em saber da onde que eles tinham saído, porque vieram? Então, eu acho que essa foi a grande motivação, assim, pra gente resgatar um pouco essas raízes, porque se a gente não faz isso, ainda que conviveu com os avós, as próximas gerações talvez não... E uma coisa, assim, que a gente sente, é que a minha irmã mais velha, ela lembra da lápide do imigrante, no cemitério em São Miguel, só que hoje não existe mais. Uma pena que isso não foi preservado. E, um dia, falando com um tio meu que ficou na 
casa onde morou o meu avô, ele me deu isso aqui, que seria a foto que teria sido mandada fazer pra colocar na lápide. Esse seria o imigrante, que seria o Pietro (mostra a foto). Então, assim, são coisas guardadas que a gente foi resgatando. (Norma, 59 anos) (Costa, 2017, p. 34-35)

O que percebemos é que, para a grande maioria, não há um interesse em ser, de fato, um italiano perante os que nasceram na Itália, mas sim, de afirmar sua diversidade perante os outros grupos em solo brasileiro. Denominar-se italiano faz mais sentido no Brasil, muitas vezes, do que na Itália, como no caso de uma de nossas entrevistadas que conta não se sentir italiana, principalmente por não saber falar o idioma, e reconhece as vantagens de ter passaporte italiano. Ela utiliza o passaporte, mas não se identifica como italiana.

Não, não porque eu tenho até o passaporte italiano, até quando eu vou, às vezes, pra viajar pro exterior eu mostro o passaporte italiano, as pessoas querem falar em italiano comigo, mas eu não sei italiano, então isso é uma coisa que dificulta. Então eu sou italiana, mas não sei nem falar o idioma. Mas eu sei que tem vantagens, eu uso as vantagens do passaporte italiano. (Maria, 51 anos) (Costa, 2017, p. 50)

O que foi possível observar com a pesquisa é que, em muitos casos, não há uma preocupação por parte desses descendentes em conhecer a língua ou determinados costumes da Itália, mas sim, em reafirmar as suas origens construídas em solo brasileiro por meio dos laços de sangue dos seus ancestrais que aqui constituíram família, histórias, trabalho e uma cultura própria. Além disso, a cidadania italiana acaba por representar status perante os demais grupos em solo brasileiro e, até mesmo, perante outros descendentes de italianos que não dispõem de condições de ingressar com o processo. Enfim, o passaporte é um sinal de distinção muito valioso no Brasil, mas não necessariamente na Itália. O reconhecimento carrega diversos significados para esses descendentes, mas o que analisamos é que a valorização étnica não está na finalidade da cidadania. Ela representa uma consequência de um direito que é garantido ao grupo, mas que se mobiliza a partir de uma compreensão da "ítalo-brasilianidade" (Costa, 2017, p. 75) que já faz parte do grupo.

\section{Os valores e significados do passaporte "vermelho"}

Mas, então, que força e valor esse passaporte carrega para continuar sendo objeto de sonho para tantos ítalo-brasileiros? O que justifica tanto tempo de espera nas filas dos consulados ou, ainda, o investimento de um alto valor econômico para fazer o processo fora do país em menor tempo, sendo que, para os italianos, esses descendentes são apenas estrangeiros ou extracomunitários como os demais?

O passaporte, além de condensar subjetividades e afetividade, torna-se, também, um símbolo de distinção no mercado simbólico local. Muitos 
descendentes fazem questão de salientar que possuem a dupla cidadania e que viajam com o passaporte italiano, não precisando, assim, enfrentar longas filas para obtenção de visto nos consulados, como no caso de viagens para os Estados Unidos, por exemplo. Ou que, estando na Europa, podem se deslocar para trabalhar em outros países sendo tratados como "italianos". Ouvimos de um entrevistado que, como em alguns países não sabiam reconhecer o sotaque da língua italiana falada pelos brasileiros, os ítalo-brasileiros eram tratados como "italianos da Itália" e que ser brasileiro não era algo tornado público. Assim, o passaporte e a documentação italiana proporcionam vantagens nas negociações trabalhistas.

Observamos que, para alguns, a conquista do passaporte é o ponto máximo de uma saga em busca da cidadania italiana. Mas, a sua representação enquanto objeto carrega valores tanto econômicos como simbólicos, adquirindo uma "vida social" (Appadurai, 2009, p. 15), tal qual as pessoas. O passaporte italiano significa para esses ítalo-brasileiros muito além do documento ou objeto que de fato ele é, simboliza a revitalização de suas origens, o que agrega a ele valor sentimental. Ele possui mana (Mauss, 1974), um valor que lhe é atribuído por meio do que podemos chamar, também, da família como patrimônio (Zanini, 2006). O passaporte objetiva e subjetiva ao mesmo tempo. Muitos descendentes costumam tirar fotografias e postar nas redes sociais quando conseguem o passaporte, apontando e atestando que o processo de reconhecimento obteve sucesso. Os objetos carregam as histórias e memórias culturalmente constituídas de cada grupo, o que acaba os transformando em símbolos dotados de significados (Kopytoff, 2009, p. 94).

Para o reconhecimento da cidadania e a obtenção do passaporte italiano há, hoje, o que se chama um "mercado da cidadania" (Santagati, 2013, p. 14-15) que se desenvolveu em torno dessa grande busca pelo reconhecimento da cidadania italiana. Nós observamos que esse mercado da cidadania agrega ao passaporte um status de mercadoria (Appadurai, 2009, p. 15), com uma vida social definida por meio das circulações estabelecidas diante das relações entre coisa e pessoa. Com isso, compreendemos que o valor agregado ao passaporte não passa apenas pelo alto custo das despesas de processo, mas também pelas diferentes ações executadas pelos indivíduos para conquistar esse documento. Ele também se torna a cristalização de uma saga familiar como patrimônio simbólico, por meio do processo que as famílias têm que montar e de toda a pesquisa que envolve traçar as genealogias, quando os indivíduos redescobrem suas histórias familiares e a si mesmos, muitas vezes. Há muitas subjetividades que são trabalhadas nesses processos de reconhecimento de cidadania (Costa, 2017, p. 63).

Isso vale tanto para quem abre o processo no Brasil como para os que se aventuram até a Itália e desembolsam valores ainda maiores. Nessa escolha, 
prevalece a questão do tempo e do custo-benefício. O Rio Grande do Sul é um dos lugares do Brasil em que o processo demora mais tempo, levando, em média, 10 anos para ser concluído. Na Itália, é possível estar com o passaporte em mãos em até 90 dias. Essa agilidade tem motivado muitos jovens que anseiam por melhores condições de vida e estudo fora do Brasil a desembolsarem esse alto valor para conseguirem o documento de forma mais rápida.

Um de nossos interlocutores, que chamamos de Rafael (37 anos), fez seu processo de reconhecimento na Itália com o auxílio de uma advogada gaúcha que já residia lá há alguns anos. Ele nos destacou que há muitas empresas e pessoas trabalhando com processos de reconhecimento da dupla cidadania na Itália. Elas preparam todas as documentações e a residência para a pessoa que chega solicitando auxílio.

Eu preciso, na verdade, pra fazer esse processo, são certidões de inteiro teor, aí, como eu sabia, tinha as certidões, fui nos cartórios aqui, peguei de inteiro teor e aí eu contratei uma tradutora em Porto Alegre, e ela fez a tradução e a legalização dos documentos no Consulado, que agora não precisa mais porque agora está valendo o tratado internacional entre Brasil e Itália, que os documentos oficiais não precisam ser traduzidos, não precisa mais ser legalizado. Mas eu fui com os documentos legalizados, e ela é que organizou com essa empresa, essa conhecida dela.... Na verdade, não era nem uma empresa. Tinha a advogada, que morava em Veneza e que estava trabalhando com cidadania. Ela é gaúcha, estava lá, e aí me indicaram, contataram ela. E ela me disse: "olha, eu preciso só de dois dias teus aqui, depois tu pode viajar". Porque era rápido, e aí em 2012 eu fui com essa finalidade. (Rafael, 37 anos) (Costa, 2017, p. 64-65)

A questão da moradia fixa é uma exigência para abertura do processo na Itália. No entanto, o que se constata é que as pessoas permanecem nessa residência apenas o tempo necessário para a visita do responsável (o vigile) por fiscalizar se a pessoa realmente está estabelecida de maneira fixa em território italiano. Ao final desse processo, muitos desses ítalo-brasileiros retornam ao Brasil. A facilitação de residências fictícias é uma fraude praticada por um grande número de agências de assessoria na Itália, mas poucos casos são detidos pelas autoridades. Uma segunda visita dos vigili pode ser solicitada para confirmar se a pessoa segue residindo no local indicado, porém, raras vezes acontece. Há dinheiro e fatores maiores em jogo (Costa, 2017, p. 66). Além dessas questões, muitos brasileiros também acabam sendo lesados por essas empresas de assessoria, que aplicam golpes. Fazendo algumas buscas rápidas pela internet, é possível encontrar um grande número de empresas oferecendo auxílio com o processo de reconhecimento em tempo mínimo, no entanto, nem todas são confiáveis. A questão do tempo é o que pesa para grande parte dos descendentes que buscam esse reconhecimento fora 
do Brasil, como no caso de Rafael, que procurou agilizar ao máximo esse processo por ter uma filha em idade escolar.

Enquanto objeto, o passaporte possui valor e representa as motivações pessoais, a importância particular que cada descendente agrega a ele, por meio da história social que ele representa, refletindo as histórias e memórias familiares que se materializam no presente, na figura desse documento. Nas histórias que ouvimos, o passaporte carrega em si as movimentações individuais desses descendentes na busca pelo reconhecimento, suas expressões culturais e conhecimentos de grupo. Trata-se de movimentos tão valiosos na compreensão do pertencimento grupal que o valor econômico e as dificuldades impostas pela "saga pelo reconhecimento" se tornam irrelevantes diante do valor simbólico agregado ao passaporte.

\section{Considerações Finais}

Em nossos estudos, identificamos que o reconhecimento da cidadania italiana representa para esses ítalo-brasileiros muito mais do que um direito jurídico-político a ser reconhecido. Há subjetividades envolvidas, há muita busca que extrapola questões práticas e objetivas e adentram no universo dos pertencimentos e suas identificações. O reconhecimento representa a legitimação legal de uma "italianidade" que já está presente no grupo por meio das memórias, hábitos e costumes trazidos pelos seus ancestrais nos séculos passados. Trata-se de uma materialização de valores simbólicos e afetivos também. O passaporte cristaliza a história vivida nas sagas familiares. É como se ela fosse "real", de fato. É uma comprovação, por isso, prevalece a ideia de reconhecimento. Ou seja, o Estado italiano os "reconhece" como iguais; mas a sociedade civil italiana, não.

Constatamos, também, que, além da comprovação dessa diversidade para o mundo, essa "italianidade" representa uma diversidade cultural em solo brasileiro. Trata-se de uma forma de demarcar sua diversidade étnica perante os outros grupos e, ainda, de obter status com relação a outros descendentes de italianos que não possuam a dupla cidadania, uma vez que observamos nas narrativas que, em muitos casos, não há o desejo de ser um nacional italiano perante os italianos de solo.

O reconhecimento da cidadania italiana ganhou força nos últimos anos, com as crises políticas e econômicas enfrentadas pelo Brasil. Os descendentes buscam melhores condições de vida e trabalho fora do país. Nesse sentido, o passaporte italiano facilita esses fluxos e mobilidades. No entanto, o que se percebe nos relatos de quem vai para a Itália por algum período é que, embora esse passaporte garanta algumas vantagens de deslocamento, o olhar dos italianos de solo para esses ítalo-brasileiros é o mesmo que eles têm para 
qualquer outro migrante brasileiro que não possua o documento. Contudo, para os descendentes, o passaporte carrega significados e representações muito fortes.

As representações envolvidas na figura do passaporte acabam por fazer com que seu valor simbólico seja mais importante que os custos econômicos que ele implica para as famílias. É essa importância que mobiliza esses ítalo-brasileiros a desembolsarem valores econômicos elevados, por vezes, para obter o documento, seja no Brasil ou na Itália. Compreendemos que o reconhecimento da cidadania italiana carrega consigo diversos e múltiplos significados para os descendentes que ingressam com o processo, independentemente da faixa etária. A cidadania representa o direito que é garantido em função da "ítalo-brasilianidade" desse grupo. O uso que dela se faz e do passaporte, seu símbolo maior para muitos, é derivado dos projetos de vida desses descendentes e de como potencializam ou não tal cidadania.

\section{Referências}

ANDERSON, Benedict. Comunidades imaginadas: reflexões sobre a origem e a expansão do nacionalismo. São Paulo: Companhia das Letras, 2008.

ANDERSON, Benedict. Problemas dos nacionalismos contemporâneos. Tensões Mundiais, Fortaleza, v. 1, n. 1, p. 16-26, jul/dez 2005.

APPADURAI, Arjun. A vida social das coisas: as mercadorias sob uma perspectiva cultural. Niterói: Eduff, 2009.

BARTH, Fredrik. Os grupos étnicos e suas fronteiras. In: LASK, Tomke (org.). O Guru, o Iniciador e Outras Variações Antropológicas. Rio de Janeiro: Contra Capa Livraria, 2000, p. 25-67.

BRAGA, Mariangela P. Descendentes de imigrantes italianos em Belo Horizonte e o impacto da dupla cidadania na construção da identidade ítalo-brasileira 1990 a 2008 (Dissertação de Mestrado em Ciências Sociais). Belo Horizonte: Pontifícia Universidade Católica de Minas Gerais, 2009.

COSTA, Jamile. Dupla cidadania: ítalo-brasilianidade como valorização e afirmação étnica no sul do Brasil (Dissertação Mestrado em Ciências Sociais). Santa Maria, RS: Universidade Federal de Santa Maria, 2017. Disponível em: <http:// w3.ufsm.br/ppgcsociais/images/dissertacoes/2015/Jamile\%20Dissertao\%20 verso\%20final.pdf >. Acesso em: abr. 2018.

COSTA, Jamile; ZANINI, Maria Catarina C. A saga pela cidadania italiana: Pertencimento e memória entre ítalo-brasileiros na região central do Rio Grande do Sul. In: ARENDT, Isabel C.; WITT, Marcos A.; SANTOS, Rodrigo L. (orgs.). Migrações: Religiões e espiritualidades. São Leopoldo: Oikos, 2016.

KOPYTOFF, Igor. A biografia cultural das coisas: a mercantilização como processo. In: APPADURAI, Arjun (org.). A vida social das coisas. Niterói: EDUFF, 2009, p. 89-121. 
MANFIO, Vanessa; BENADUCE, Gilda M. C. A Quarta Colônia de Imigração Italiana: A valorização cultural da região. In: Anais XIV Simpósio de Ensino, Pesquisa e Extensão: Responsabilidade socioambiental, v. 1, 2010. Santa Maria: UNIFRA, 2010, p. 1-8. Disponível em: <http://www.unifra.br/eventos/sepe2010/2010/ Trabalhos/humanas/Completo/4596.pdf> . Acesso em: 08.09.2017.

MAUSS, Marcel. Sociologia e Antropologia. V. II, São Paulo: EPU, 1974.

ONG, Aihwa. Flexible citizenship. The cultural logics of transnationality. Duke University Press, 1999.

PERON, Desiderio. Reconhecimento da cidadania italiana na Itália "está no limbo", diz o cônsul Nicola Occhipinti. Insieme - A revista italiana daqui, 21.10. 2016. Disponível em: <http:/www.revistainsieme.com/single-post/2016/10/21/ Reconhecimento-da-cidadania-italiana-na-Itália-“está-no-limbo"-diz-o-cônsulNicola-Occhipinti>. Acesso em: 13.01.2017.

PICCOLI, Beatriz. Lei no 91, de 05 de fevereiro de 1992. Dupla cidadania na Itália, 29.08.2013. Disponível em: <http://duplacidadanianaitalia.blogspot.com. br/2013/08/dupla-cidadania-na-italia-lei-05.html> . Acesso em: 09.05.2016.

REIS, Rossana R. Soberania, direitos humanos e migrações internacionais. RBCS, v. 19, n. 55, jun. 2004. Disponível em: <http://www.scielo.br/pdf/rbcsoc/ v19n55/a09v1955.pdf>. Acesso em: 12.10.2015.

SANTAGATI, Mariagrazia. Jovens brasileiros, descendentes de italianos: relações transnacionais e significados da dupla cidadania. Cadernos de Pesquisa, São Luís, v. 20, n. 2, p. 6-22, 2013.

SANTOS, Miriam de O.; ZANINI, Maria C. C. Especificidades da identidade de descendentes de italianos no sul do Brasil: breve análise das regiões de Caxias do Sul e Santa Maria. Revista Antropolítica, Niterói, n. 27, p. 21-41, 2009.

SAVOLDI, Adiles. O caminho inverso: a trajetória de descendentes de imigrantes italianos em busca da dupla cidadania (Dissertação Mestrado em Antropologia Social). Florianópolis: Universidade Federal de Santa Catarina, 1998.

SCHILLER, Nina G.; BASCH, Linda; BLANC, Cristina S. From Immigrant to Transmigrant: Theorizing Transnational Migration. Anthropological Quarterly, v. 68, n. 1, p. 48-63, jan. 1995.

STOLF, Elton D. A cooperação não governamental para o reconhecimento da nacionalidade italiana (Dissertação de Mestrado em Direito). Florianópolis: Universidade Federal de Santa Catarina, 2012.

TEDESCO, João Carlos. Casamentos mistos: novas sociabilidades e quadros coletivos. Aspectos da imigração de brasileiras na Itália. Estudos Feministas, Florianópolis, v. 22, n. 1, p. 115-133, mai. 2014. Disponível em: < https://periodicos.ufsc.br/ index.php/ref/article/view/S0104-026X2014000100007/26803>. Acesso em: 06.04.2017.

VERTOVEC, Steven. Transnationalism. London/New York: Routlegde, 2009.

ZANINI, Maria C. C. Italianidade no Brasil Meridional: a construção da identidade étnica na região de Santa Maria - RS. Santa Maria: Editora da UFSM, 2006. 
ZANINI, Maria C. C. Um olhar antropológico sobre fatos e memórias da imigração italiana. Mana, Rio de Janeiro, v. 13, p. 521-547, 2007.

ZANINI, Maria C. C. Mídias, italianidades e pertencimentos étnicos no sul do Brasil (Brasil) - Ebook. In: COGO, Denise; ELHAJJI, Mohammed; HUERTAS, Amparo (orgs.). Diásporas, migrações, tecnologias da comunicação. Barcelona (Espanha): Editora Bellaterra, 2012, p. 283-298.

ZANINI, Maria C. C.; ASSIS, Glaucia; BENEDUZI, Luis Fernando. Cidadãos de direito, estrangeiros de fato: narrativas de ítalo-brasileiros (as) na Itália. História Oral, v. 18, n. 1, p. 117-145, jan./jun. 2015.

ZINCONE, Giovanni (org.). Familismo legale: come (non) diventare italiani. RomaBari: Editori Laterza, 2006. 